\title{
PATRULHEIROS DA MORALIDADE: OS CENSORES diaNte de UMA PEÇA de NELSON RODRIGUES
}

http://dx.doi.org/10.11606/issn.2237-1184.v0i24p68-77

\author{
Adriano de Paula Rabelo \\ Universidade Estadual de Campinas (UNICAMP)
}

RESUMO

Este artigo analisa as relações do dramaturgo Nelson Rodrigues com a Censura do estado de São Paulo no início dos anos 1960, através da peça Boca de Ouro, tal como essas relações estão documentadas no prontuário $\mathrm{N}^{\circ}$. 4906 do Arquivo Miroel Silveira, na Escola de Comunicações e Artes da Universidade de São Paulo. Interessa ao autor discutir como os parâmetros morais são inadequados para o julgamento de uma obra de arte, expondo os equívocos em que a atividade censória sempre recai em sua tentativa de conter a liberdade da criação artística em nome de concepções e comportamentos considerados "adequados" ou "normais".

\section{ABSTRACT}

This article is about the censorship to Nelson Rodrigues's play Boca de Ouro in the beginning of the 1960's, in the state of São Paulo, Brazil. The documents then issued by the censors now belong to dossier number 4906 in Miroel Silveira Archive at the School of Communication and Arts of the University of São Paulo. The author discusses how moral criteria are inadequate do judge a work of art and exposes the mistakes censors always make every time they try to restrain freedom of artistic creation in the name of conceptions and behavior reputed as "normal" or "adequate".
PALAVRAS-CHAVE:

Nelson Rodrigues.

Boca de Ouro.

Censura.

Liberdade de expressão.

KEYWORDS:

Nelson Rodrigues.

Boca de Ouro.

Censorship.

Freedom of speech. 


\section{arquivo Miroel Silveira e a repressão do Estado ao teatro}

O Arquivo Miroel Silveira, hoje sob a guarda da Escola de Comunicações e Artes, da Universidade de São Paulo, compõe-se por um volume significativo de dossiês produzidos pelo Serviço de Censura do Departamento de Diversões Públicas do Estado de São Paulo ao longo de 40 anos, abrangendo os dois últimos períodos ditatoriais da história brasileira: a era Vargas (de 1930 a 1945) e a Ditadura Militar (de 1964 a 1985), além do período relativamente democrático entre esses dois regimes autoritários, quando a instituição da Censura continuou ativa e muito atuante no cerceamento da liberdade de expressão no país. Os milhares de documentos constantes no arquivo contam a história da mentalidade das forças conservadoras no Brasil daquele período, bem como da perseguição sofrida pelo teatro paulista de então.

Especialmente numa época anterior ao desenvolvimento da televisão e do chamado show business, o teatro possuía um impacto social considerável, sendo constantemente perseguido pela Censura em virtude de suas ousadias expressivas, posturas críticas e atitudes libertárias. Os conflitos entre a arte teatral dos grandes centros e o autoritarismo político que tem marcado a história brasileira tiveram seu ápice nos primeiros anos da Ditadura Militar, quando especialmente os palcos de São Paulo e do Rio de Janeiro estiveram entre as principais frentes de resistência às imposições do governo de exceção que usurpou o poder em 1964. Assim como em outras artes, naquela época houve, no teatro, o desenvolvimento de todo um projeto nacional-popular encabeçado por grupos como o Teatro de Arena, o Oficina e o Opinião, além da dramaturgia e dos espetáculos produzidos pelos Centros Populares de Cultura da União Nacional dos Estudantes e das teorias e práticas do Teatro do Oprimido, de Augusto Boal. Em geral, esse movimento produziu uma arte engajada no debate sobre os problemas nacionais, na luta por justiça social e na promoção dos direitos da cidadania, o que resultou numa constante perseguição do teatro por parte dos órgãos repressivos da ditadura, em especial por meio da Censura, mas, se preciso fosse, também da polícia, da ação ilegal de membros as forças armadas e de vistas grossas para incursões violentas de grupelhos civis de extrema direita. Em O Teatro sob Pressão: Uma Frente de Resistência, Yan Michalski, ao analisar a produção teatral brasileira de 1968, ano que terminou com uma completa supressão das possibilidades de oposição ao regime ditatorial, escreve: "Uma ampla campanha de difamação do teatro é desencadeada, insistindo na 
'imoralidade' dos espetáculos e na quantidade de palavrões ditos nos palcos. Aos poucos, começa a configurar-se também uma ofensiva de órgãos paramilitares contra o teatro: multiplicam-se as ameaças, as condições de trabalho tornam-se muitas vezes inseguras".

\section{Nelson Rodrigues no Arquivo Miroel Silveira}

Um dos autores mais presentes nos processos da Censura paulista é Nelson Rodrigues. No Arquivo Miroel Silveira há um total de 13 dossiês relacionados a peças suas que foram obrigadas a passar pelo crivo dos censores antes de poderem ser apresentadas nos palcos do estado de São Paulo. Entre as obras censuradas estão A Mulher sem Pecado, Vestido de Noiva, Anjo Negro, Senhora dos Afogados, Vinde Ensaboar Vossos Pecados (adaptação de Doroteia), Valsa No. 6, A Falecida, Perdoa-me por me Traíres, Viúva, porém Honesta, Boca de Ouro e Toda Nudez Será Castigada. A primeira delas a receber o Certificado de Censura - documento que estabelecia se e com quais restrições uma obra de teatro podia ser encenada - foi Anjo Negro, considerada como "Imprópria para menores de 18 anos" em documento expedido em 28 de janeiro de $1949 ;^{2}$ e a última foi A Falecida, também liberada com a mesma restrição no dia 21 de outubro de $1966 .^{3}$

Nesses dossiês, chamam a atenção as constantes alegações de "imoralidade" por parte dos censores para impugnar total ou parcialmente várias peças de Nelson Rodrigues. O parecer do censor Marcio de Assis Brasil de 2 de junho de 1951, sobre A Mulher sem Pecado, é típico. Após classificá-la como "comédia dramática absolutamente imprópria para ser representada no auditório do Instituto Caetano de Campos", ${ }^{4}$ ele escreve:

Julguei de bom alvitre cortar da folha 21 até o final da peça á [sic] folha 23, onde o assunto mais escabroso se torna, sendo que neste final é que se consuma aquilo que tanto o marido insistiu com a mulher, pois ela foge com outro, deixando uma carta em que revela sua resolução. ${ }^{5}$

Adjetivos como "impróprio", "imoral", "escabroso", "indigno", "constrangedor", "indecente", "lamentável", "deplorável", "chocante", "grosseiro", "aberrante", "desagregador" são frequentemente utilizados nos pareceres para qualificar o trabalho de Nelson Rodrigues e justificar sua proibição ou mutilação. Anexos aos dossiês, também chamam a atenção cartas, abaixo-assinados e outras petições de organizações conservadoras que patrulhavam da moralidade e tinham certa ressonância

\footnotetext{
${ }^{1}$ MICHALSKI, Yan. O Teatro sob Pressão: Uma Frente de Resistência. Rio de Janeiro: Zahar, 1985, p. 34.

${ }^{2}$ Prontuário $\mathrm{N}^{\circ} .2759$, Arquivo Miroel Silveira.

${ }^{3}$ Prontuário $N^{\circ}$. 1731, Arquivo Miroel Silveira.

${ }^{4}$ Prontuário No. 3136, Arquivo Miroel Silveira.

${ }^{5}$ Ibidem, grifo do censor.
} 
nos anos 1950 e 60, como a Cruzada das Senhoras Católicas, o Movimento de Arregimentação Feminina e a Ação Católica de São Paulo. Desta última, por exemplo, há um abaixo-assinado com 1401 assinaturas pedindo a interdição de Perdoa-me por me Traíres. Nessa petição há folhas timbradas de várias paróquias da cidade de São Paulo, o que sugere um esforço concentrado para a coleta de um volume significativo de assinaturas que davam suporte à proibição da peça. Na grande maioria dos casos, porém, as obras de Nelson Rodrigues foram liberadas para encenação com cortes e restritas a maiores de 18 anos.

\section{O prontuário $\mathrm{N}^{\circ} .4906$, relacionado à peça Boca de Ouro}

Antes de entrar na análise dos documentos da Censura paulista em relação a Boca de Ouro, talvez seja importante resumir brevemente seu enredo. Escrita em 1959, a peça conta a história de um bicheiro do bairro de Madureira, no Rio de Janeiro, que, nascido numa pia de gafieira e tendo tomado seu primeiro banho com água de bica, após tornar-se adulto e enriquecer em sua atividade ilegal manda substituir toda a sua dentição perfeita por uma arcada completa de dentes de ouro puro como forma de se vingar de suas origens humildes. Recheada por temas e procedimentos recorrentes nas obras do dramaturgo, como obsessões e paroxismos sexuais, morbidez, ironia feroz, exposição da hipocrisia dentro da estrutura familiar burguesa, violência, críticas à imprensa e recriação da linguagem popular, a peça se constrói em torno das lembranças de dona Guigui, ex-amante de Boca de Ouro. Ela apresenta três versões sobre a personalidade do bicheiro, influenciada inicialmente pela mágoa de ter sido abandonada por ele, depois pelo impacto da notícia de sua morte e finalmente pela ameaça de ser deixada também pelo marido atual, enciumado pela construção positiva do perfil do morto na segunda versão. Seja qual for a versão que mais se aproxima da realidade, no entanto, no final da peça, bem ao estilo de Nelson Rodrigues, somos informados de que o cadáver de seu protagonista foi conspurcado no cemitério, onde ladrões roubaram-lhe a dentadura de ouro, símbolo de sua ilusória vitória sobre as vicissitudes da condição humana. ${ }^{6}$ É essa história e a maneira de representá-la no palco que melindrou a Censura paulista e as organizações conservadores que protestaram contra a peça e deram suporte a sua interdição.

No dia 31 de agosto de 1960, a Sociedade Brasileira de Autores Teatrais expediu um documento reconhecendo os direitos de representação de Boca de Ouro em São Paulo pela Companhia Brasileira de Comédia, do empresário teatral Rubens de Falco Costa. Data do mesmo dia a assinatura de um contrato de representação da peça. Em seguida, a

${ }^{6}$ RODRIGUES, Nelson. Boca de Ouro. Rio de Janeiro: Nova Fronteira, 2012. 
obra foi submetida à censura da Divisão de Diversões Públicas da Secretaria de Segurança Pública do Estado de São Paulo. O pedido foi protocolado no mesmo dia pelo próprio produtor da peça, com previsão para estreia em 5 de outubro de 1960. No dia 2 de setembro, houve uma solicitação de registro do contrato de representação na mesma Divisão de Diversões Públicas. Todos esses processos se mostram muito burocratizados, com necessidade de registro em cartório e carimbo das várias instâncias pelas quais a solicitação de censura passava no âmbito da Secretaria de Segurança Pública do Estado de São Paulo.

O que mais chama a atenção no prontuário, porém, são os três pareceres produzidos pelos censores José Salles, Aloysio de Oliveira Ribeiro e J. Pereira, este último também diretor da Divisão de Diversões Públicas, no dia 16 de setembro de 1960. Seus argumentos deixam bastante claro que a censura ao teatro, em especial a Nelson Rodrigues, guiava-se por critérios morais na abordagem de algo que deveria ser julgado por parâmetros estéticos. Tais censores, funcionários concursados do Estado, atuavam como guardiães de uma moralidade pública extremamente conservadora. A indignação e a ira com que analisam e julgam Boca de Ouro fazem com que, pela forma exagerada como condenam a peça, suas avaliações frequentemente descambem para o cômico.

Em seu longo parecer, José Salles informa, de maneira um tanto suspeita, que a Censura paulista "tem estudado, com carinho" temas escabrosos, apresentando uma longa lista dos mesmos:

...incesto, adultério, concubinato, complexo de Édipo, estrupo [sic], defloramento, depravação moral, homicídio, fratricídio, uroxidio [sic], infanticídio, caftinismo, prostituição ou proxenetismo, sadismo, paixões lascivas, contato carnal, impudícia [sic], cárcere privado, constrangimento físico (vis absoluta), constrangimento moral (vis compulsiva), gozos genésicos, concuspcência [sic], libidinosidade, lesbianismo, narcisismo sexual, ferocidade ou atrocidade, etc. ${ }^{7}$

Em seguida, Salles expõe uma espécie de teoria da censura, lançando mão de conceitos muito vagos e abstratos para justificar o moralismo que tem como referência:

No exame ou censura de qualquer matéria que é atribuída à Censura, esta tem por dever levar em consideração não só qualquer ofensa ao decoro público, como, ainda, impedir (restringindo ou negando autorização), [sic] representação que contiver cenas de ferocidade, que for capaz de sugerir prática de crimes, que divulgar ou induzir aos maus costumes e outras inconveniências previstas.

Há o conceito de que "Censura" é a consciência da coletividade.

\footnotetext{
${ }^{7}$ Parecer de José Salles no prontuário No. 4906, Arquivo Miroel Silveira.
} 
É, pois, "Censura", a consciência que aprecia a arte dramática de real valor, distinguindo o próprio do impróprio, o limpo do sujo. ${ }^{8}$

O que seriam, por exemplo, "decoro público", "maus costumes", "inconveniências", "consciência da coletividade"? Não há, em seu julgamento, uma definição de expressões tão imprecisas e sujeitas às mais variadas interpretações.

Imbuído de seu papel de policial da "consciência da coletividade", o censor paulista declara que "não pode aceitar as manifestações amorais, repulsivas, asquerosas, imundas e chocantes, acobertadas pelos defensores do falso modernismo, e, [sic] de outras aberrações que enfraquecem a nossa estrutura social e moral". ${ }^{9}$ Referindo-se sempre a Boca de Ouro como uma "peça" (entre aspas), José Salles considera que ela está a serviço de uma "propaganda velada, que vai semeando o desrespeito ao lar, o desrespeito às tradições religiosas e, como interessa a certos doutrinadores, a desmoralização completa da estrutura social, sem respeito à sensibilidade alheia". ${ }^{10}$ A única preocupação da "peça" seria "apresentar quadros fortes, sem qualquer propósito de uma lição moral ou construtiva". ${ }^{11}$ Essas apreciações mostram que o censor sobre-estima, de forma por demais exagerada, o poder da peça de Nelson Rodrigues para transformar as pessoas, conduzindo-as pela senda do mal e abalando as estruturas da sociedade paulista. Em toda a milenar história do teatro, não se tem notícia de peça alguma que tenha conseguido realizar tal façanha. Por outro lado, seus juízos revelam alguém completamente despreparado para compreender uma obra de arte, qualquer que seja a forma de sua expressão. Há muito tempo que já é ponto pacífico entre os teóricos da literatura que ela não tem de apresentar nenhuma lição moral nem de ser construtiva ou edificante.

Por fim, após considerar que a peça chafurda na "indecência" e na "licenciosidade" através de "inflexões, intonações [sic] maliciosas", "gestos condenáveis" que buscam "induzir aos maus costumes, como exemplo a ser imitado", que ela "nada contém de construtivo ou educacional, muito deixando a desejar quanto ao aspecto moral" e que faz "apologia direta e indireta de crimes", ${ }^{12}$ Salles apresenta seu veredito, propondo a interdição de encenações da obra: "Esta Censura julga a presente peça teatral intitulada 'Boca de Ouro', de autoria de Nelson Rodrigues, IMPRÓPRIA para ser apresentada a qualquer plateia, PROIBINDO-A para os fins de representação pública, para todo o Estado [sic] de São Paulo". ${ }^{13}$

\footnotetext{
${ }^{8}$ Ibidem.

${ }^{9}$ Ibidem.

${ }^{10}$ Ibidem.

${ }^{11}$ Ibidem.

${ }^{12}$ Ibidem.

${ }^{13}$ Ibidem, grifos do censor.
} 
Outro censor, Aloysio de Oliveira Ribeiro apresenta um parecer bem mais conciso mas não menos eloquente que o de seu colega:

O autor é um monstro, um doente ou um calculista frio, [sic] que procura, através de um punhado de imundicies [sic], agredir a sociedade, solapar a sua estrutura moral, destruir os princípios que devem nortear e sustentar a sagrada instituição da família.

Observa-se um conjunto de fraquezas humanas, reunindo a lama que integra o teatro da vida, onde [sic] o autor desconhece o que é belo e não sabe o que é nobre. ${ }^{14}$

Por fim, a decisão de Ribeiro sobre o destino da peça segue na mesma linha: "Nada há de construtivo. O texto obriga a sua impugnação. $\mathrm{O}$ autor merece pena." ${ }^{15}$

Se o primeiro censor exagerava a capacidade de impacto social da peça de Nelson Rodrigues, este segundo, em seu alarmismo, toca as raias do delírio. Além disso, ele faz uso de termos absolutamente impróprios num parecer de um representante do Estado, a quem, em sua função, caberia apresentar um parecer sobre a peça calcado num mínimo de sobriedade e elegância, resistindo a fazer esse apaixonado e subjetivo julgamento moral do autor. Por outro lado, reações como esta eram típicas daquelas que faziam com que o dramaturgo exultasse, já que para ele "a verdadeira apoteose é a vaia". ${ }^{16}$ Mas obviamente Nelson Rodrigues não se alegraria com a proibição de sua peça e por certo denunciaria com sarcasmo a pouca inteligência e a incompreensão por detrás desse tipo de reação.

Um terceiro censor, de nome J. Pereira, inicia sua apreciação reconhecendo o "inegável talento e a reconhecida cultura" de Nelson Rodrigues, mas, citando uma passagem de Gilberto Amado, ressalta que "há sujeitos que não merecem o talento com que nasceram". Considerando que o dramaturgo rompeu todos "os limites da autêntica liberdade de expressão" e "ultrapassou - e muito - as fronteiras da coragem e da audácia", Pereira confessa sentir-se constrangido ao dizer que "trata-se de uma peça suja! Não dignifica a ribalta. Ao contrário, emporcalhando-a, conspurcá-la-ia, se autorizada a sua encenação". Considera ainda que a obra "ultrapassa o lamentável, posto ser deplorável", que "não constrói, destrói. Não eleva, degrada e deprime". Por fim, o teatro do autor de Boca de Ouro é rotulado como "sujo e, sobretudo, desagregador". O mais patético, no entanto, talvez seja o momento em que o chefe do setor de Censura do estado de São Paulo se julga no direito de fazer recomendações para que o dramaturgo realize seu talento de forma apropriada: "se [Nelson Rodrigues] soubesse, como criador, impor-se a si mesmo os limites da autêntica liberdade de

\footnotetext{
${ }^{14}$ Parecer de Aloysio de Oliveira Ribeiro no prontuário No. 4906, Arquivo Miroel Silveira.

${ }^{15}$ Ibidem.

${ }^{16}$ RODRIGUES, Nelson. "O autor como um ladrão de cavalos". In: O Reacionário. São Paulo: Companhia das Letras, 1995 , p. 288
} 
expressão, através da arte que escolheu para manifestar as suas mensagens, certamente nos daria, como ainda poderá nos dar, trabalhos corajosos, audaciosos mesmo, sem serem, entretanto, fesceninos". ${ }^{17}$

\section{Conclusão}

Em suas teorizações sobre o "teatro desagradável", um teatro que provoca no espectador (neste caso, no censor) uma espécie de repulsa fascinada, Nelson Rodrigues justifica esteticamente a validade das aberrações que explora em sua dramaturgia:

...jamais discuti ou refutei a minha morbidez. Dentro de minha obra, ela me parece incontestável e, sobretudo, necessária. Artisticamente falando, sou mórbido, sempre fui mórbido, e pergunto: "Será um defeito?" Nem defeito, nem qualidade, mas uma marca de espírito, um tipo de criação dramática. (...) Peçam tudo, menos que eu renuncie às atrocidades habituais dos meus dramas. Considero legítimo unir elementos atrozes, fétidos, hediondos ou o que seja, numa composição estética. Qualquer um pode, tranquilamente, extrair poesia de coisas aparentemente contraindicadas. Isso é tão óbvio que me envergonho de repeti-lo. ${ }^{18}$

Portanto, de acordo com as concepções do dramaturgo, o único critério legítimo para o julgamento de suas obras é o estético, pois para ele a exploração de qualquer temática é legítima. Isso é praticamente uma inversão das crenças dos censores, que se consideravam protetores da moralidade da, a seu ver, imatura e muito influenciável sociedade paulista, cujas instituições correriam risco de desagregação, caso peças como as de Nelson Rodrigues fossem liberadas para todas as pessoas. Estas, depois de assisti-las, poderiam passar a se comportar como os personagens que viam em cena, conforme os técnicos da Censura. Como se viu, a qualificação estética das obras do autor de Boca de Ouro, que o consagraram como o maior dramaturgo brasileiro, não são levadas em consideração nessas vagas apreciações moralizantes e vazadas em linguagem às vezes bastante precária. A leitura dos censores é tão pobre que, se reparassem bem, veriam que, embora nada convencional, Nelson Rodrigues é um grande moralista a mostrar o que acontece caso nossos instintos primitivos não sejam reprimidos, embora ele pareça acreditar que eles quase sempre predominem sobre as normas e convenções. Além disso, as transgressões de caráter moral que o dramaturgo explora em seu teatro jamais terminam sem punição, o que ocorre geralmente ao final de suas peças. O próprio Boca de Ouro, protagonista da obra homônima, ao fim de uma vida de crimes, termina assassinado por uma de suas amantes e tem seus vistosos

\footnotetext{
${ }^{17}$ Todos os excertos citados no parágrafo estão no parecer de J. Pereira no prontuário $\mathrm{N}^{\circ}$. 4906, Arquivo Miroel Silveira.

${ }^{18}$ RODRIGUES, Nelson. "Teatro desagradável". In: Dionysos. Rio de Janeiro: SNT/MEC, n 1, Outubro de 1949, pp. 11 e 13.
} 
dentes de ouro, símbolo de seu poder, arrancados por ladrões que invadem o necrotério para onde seu cadáver fora enviado para os procedimentos legais.

As reações dos censores, no entanto, não diferem daquelas de grande parte do público e mesmo da crítica teatral. Até os anos finais da década de 1960, Nelson Rodrigues será constantemente associado à imagem do "tarado de suspensórios" com que celebrizou-se a partir da escrita de peças como Álbum de Família, Anjo Negro, Senhora dos Afogados e Doroteia na segunda metade da década de 1940, trabalhos que notabilizaram-se pelos escândalos e pelas polêmicas que suscitaram. $\mathrm{O}$ próprio dramaturgo, identificando a potencialidade promocional do rótulo que lhe pespegaram, contribuiu bastante para a consagração dessa imagem redutora de sua persona pública. No entanto, tachá-lo de "tarado", "pornográfico", "monstro", "doente" é tão absurdo quanto aplicar rótulos semelhantes aos grandes tragediógrafos gregos, que também abordaram temas "desagradáveis" ao recontarem as histórias de Édipo, Electra, Orestes, Clitemnestra, Fedra, Medeia e tantos outros. Nos anos 1950 e 60 ocorreram grandes mudanças nos padrões de comportamento tradicionais. Assim, a imaturidade que os censores atribuíam ao público era por certo uma característica deles mesmos, que trabalhavam fora de sintonia com as transformações da sociedade brasileira de seu tempo.

A reputação de "indecente" acompanhará Nelson Rodrigues até os anos finais da década de 1960, quando, em virtude de seus posicionamentos políticos, explicitados em crônicas que publicava diariamente na imprensa, ele será tachado como "reacionário", o que, num tempo de forte polarização ideológica, terá grande impacto na recepção e avaliação de seu teatro. Ruy Castro chama a atenção para isso na introdução a sua biografia de Nelson:

Durante muitos anos, Nelson Rodrigues carregou a fama de "tarado". Em seus anos finais, a de "reacionário". Ninguém foi mais perseguido: a direita, a esquerda, a censura, os críticos, os católicos (de todas as tinturas) e, muitas vezes, as plateias - todos, em alguma época, viram nele o anjo do mal, um câncer a ser extirpado da sociedade brasileira. E, olhe, quase conseguiram. ${ }^{19}$

Quando publicou suas memórias na forma de crônicas diárias no jornal Correio da Manhã, de fevereiro a maio de 1967, Nelson, já com 54 anos e uma experiência de vida extraordinária, buscou mostrar uma imagem mais humanizada de si, diferente daquela do teatrólogo escandaloso e do acerbo polemista com que se tornara conhecido, apresentando-se como um ser humano comum, possuidor de virtudes e defeitos, com uma existência marcada por sofrimentos e também momentos de felicidade, tal como a vida de todo mundo. Esse era o Nelson

${ }^{19}$ CASTRO, Ruy. O Anjo Pornográfico: A Vida de Nelson Rodrigues. São Paulo: Companhia das Letras, 1992, p. 8. 
Rodrigues com quem privavam as pessoas próximas dele. Suas figurações públicas, no entanto, preservarão até o fim o espírito polêmico, a postura provocadora, a incitação à crítica e o gosto pela publicidade de suas realizações. Hoje, passadas as polêmicas em que ele se envolveu, passadas as ditaduras que assolaram o país ao longo do século XX, passada a própria instituição da Censura, o que permanece é uma obra amplamente reconhecida como o que de melhor se produziu na história do teatro brasileiro e um escritor reconhecido como um dos maiores de nossa literatura.

Recebido em 19/04/2017 Aprovado em 20/06/2017 